\title{
Awareness on Risk Factors of Lymphoma Among College Students
}

\author{
Taanya Imtiaz' ${ }^{1}$ Vishnu Priya. $V^{2}$ and Gayathri. $\mathrm{R}^{3}$ \\ ${ }^{1}$ Saveetha Dental College and Hospitals Saveetha Institute of Medical \& Technical \\ Sciences (SIMATS) Saveetha University Chennai-600077, India \\ ${ }^{2}$ Department of Biochemistry Saveetha Dental College and Hospitals Saveetha Institute \\ of Medical \& Technical Sciences (SIMATS ) Saveetha University Chennai-600077, India \\ ${ }^{3}$ Department of Biochemistry Saveetha Dental College and Hospitals Saveetha Institute of \\ Medical \& Technical Sciences ( SIMATS ) Saveetha University Chennai-600077, India
}

\section{ABSTRACT}

Lymphoma is a type of blood cancer caused due to lymphocytes which is a white blood cell that multiplies in this disease. It is a cancer of the lymphatic system which includes lymph nodes, bone marrow, thymus, spleen. Gastro-intestinal tract, spleen and bone marrow are frequently involved in the diagnosis of late stage lymphomas. Non-Hodgkin (NHL) and Hodgkin are the 2 main types of lymphoma. Main symptoms of lymphoma may include enlargement of lymph nodes of the neck, armpit and groin regions without any pain experience and persistent sweating. Early diagnosis is pertinent in lymphomas when compared to other cancers. The aim of the study is to create awareness on risk factors of lymphoma among college students. The survey was conducted among 170 college students. The questionnaire consisted of 15 questions about lymphoma and its risk factors, pathogenesis and treatment modalities. More than 94\% of the students are aware about lymphoma, 72\% are aware about lymphoma being a complex cancer and 54.3\% are aware that it can be cured at the right stage. Advancement in treatment modalities have improved the prognosis of patients with lymphoma.

KEY WORDS: AWARENESS; KNOWLEDGE; LYMPHOMA; RISK FACTORS; SURVEY PLANET.

\section{INTRODUCTION}

Lymphoma is a type of blood cancer, different from leukemia (Zheng et al., 2017). Different types of cells present in our body start up different types of cancer and lymphocytes are the cells responsible for lymphoma (Zheng et al., 2017) (Wang et al., 2017) . Lymphoma starts involving the lymphocytes of our immune body i.e., T cells or B cells (Ball, 2017) . Main symptoms of lymphoma

\section{ARTICLE INFORMATION}

${ }^{*}$ Corresponding Author: vishnupriya@saveetha.com

Received 20th July 2020 Accepted after revision 23rd Sep 2020

Print ISSN: 0974-6455 Online ISSN: 2321-4007 CODEN: BBRCBA

Thomson Reuters ISI Web of Science Clarivate Analytics USA and Crossref Indexed Journal

\section{Clarivate
Analytics}

NAAS Journal Score 2020 (4.31) SJIF: 2020 (7.728)

A Society of Science and Nature Publication,

Bhopal India 2020. All rights reserved.

Online Contents Available at: http//www.bbrc.in/

Doi: http://dx.doi.org/10.21786/bbrc/13.8/173 may include enlargement of lymph nodes of the neck, armpit and groin regions without any pain experience and persistent sweating. Non-Hodgkin and Hodgkin are the 2 main types of lymphoma (Lynce et al., 2012). Around 5-10\% of the non-Hodgkin lymphomas represent mantle cell lymphoma which is an aggressive malignancy of B cells (Kostareli et al., 2012) (Hadzidimitriou et al., 2011) (Agathangelidis et al., 2019).

In the 2nd half of the century, there is an unusual increase in the incidence of non-Hodgkin lymphomas (Hjalgrim et al., 1996) (Varterasian et al., 2000) (McNally et al., 1997) (McNally et al., 1999) (Cartwright et al., 1999) (Cartwright et al., 1994) (Cartwright, 1992) (Groves et al., 2000) (ST Boyle P Holford TR Liu WL Flannery J, n.d.) (Seow A, Lee J, Sng I, Fong CM, Lee HP, n.d.) (Di Lollo S Picoco C, n.d.) (Liu et al., 2003). The classification of NHL comes under the heterogeneous group of malignancies under lymphoproliferative (Harris et al., 2000) . The pathway

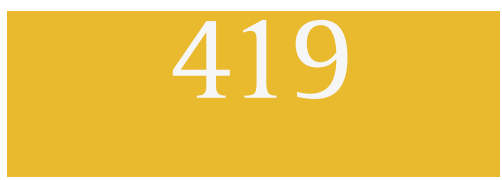


leading to the diagnosis can be complex and time consuming. Early diagnosis is pertinent in lymphomas when compared to other cancers (Allgar and Neal, 2005). These diseases are associated with fluctuating symptoms, seeking help for a long period, taking many primary consultations and opinions before referring a secondary care (Allgar and Neal, 2005) (Howell et al., 2006) (Swann et al., 2018) (Elliss-Brookes et al., 2012).

The United Kingdom has introduced a range of interventions to promote early diagnosis of the disease (Richards et al., 2011). However, a mixed impact has been noted (Neal et al., 2014). Gastro-intestinal tract, spleen and bone marrow are frequently involved in the diagnosis of late stage lymphomas (Richards et al., 2011). Traditionally classified into leukemia, Hodgkin lymphoma, non-Hodgkin lymphoma and myelomas which actually comprises more than $60 \%$ of the subtypes of complex cancer which has different onset, diagnosis and treatment (Postgraduate Haematology, 2015).

Allogeneic hematopoietic stem cell transplant is offered in routine to expect betterment of the lymphoma (Richards et al., 2011)(Neal et al., 2014)(Postgraduate Haematology, 2015). The current research is about the finding of hematological malignancies, and focusing on the symptoms getting common for these diseases. Hematological malignancies are the most common collectively fourth placed cancer diagnosed in both females and males in economically developed places in the world (Jemal et al., 2008) (Hartge and Devesa, 1992). Previous studies on cancer biology, nano materials, herbal products (Ponnulakshmi et al., 2019) (Wu et al., 2019) (Ke et al., 2019) (Ma et al., 2019) (Li et al., 2020) (Chen et al., 2019) have motivated me to pursue this current research which is useful to our community. The aim of this study is to create awareness about lymphoma and its risk factors among college students.

\section{MATERIAL AND METHODS}

A questionnaire was prepared and administered to 170 college students in Chennai, Tamilnadu through an online survey planet link. The questionnaire consisted of 15 questions which were related to risk factors, age group, pathogenesis and treatment modalities. Data was collected from the link generated and statistically analyzed. Pie chart was used for the representation of the data collected. Dependent variables of this study were knowledge and awareness. Independent variables of this study were caste, occupation, gender, height, weight etc.

\section{RESULTS AND DISCUSSION}

The data was collected and statistically analyzed. Figure 1 depicts $94.7 \%$ of students know that lymphoma is a life-threatening disease all over the world. Figure 2 shows that people are less aware that both lymphoma and leukemia together involve more than $70 \%$ of the complex cancer in the world. Figure 3 shows that 54\% of the population are aware that lymphoma can be cured at the right stage if diagnosed. Figure 4 shows that 57\% of the students are aware that lymphoma diagnosis causes impairment of the immune system. Figure 5 shows that more than $68 \%$ of the students are aware about the present treatment methods i.e., chemotherapy and radiations are performed to treat lymphoma.

Figure 1: This pie chart represents percentage distribution of responses about awareness on lymphoma. Purple denotes yes and blue denotes no that lymphoma is a threatening disease. Majority of the students (94\%) responded as lymphoma being a threatening disease.

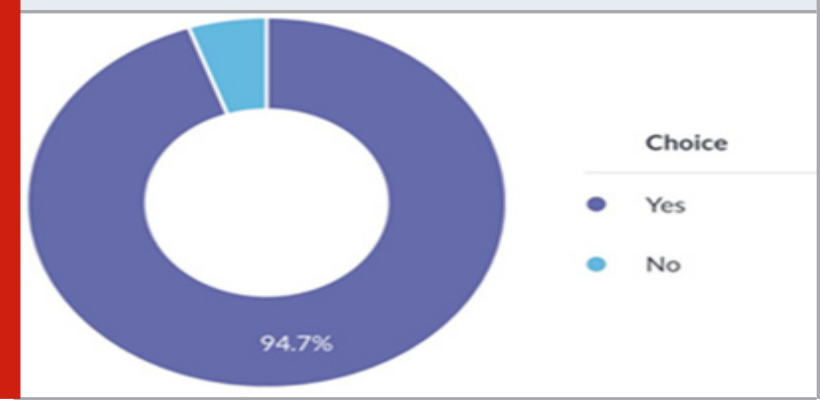

Figure 2: This pie chart represents percentage distribution of responses about awareness on lymphoma and leukemia being the major complex cancers around the world. Purple denotes yes and blue denotes lymphoma and leukemia being the complex cancers. Majority of the students (72\%) are not aware about lymphoma and leukemia being the complex cancers around the world.

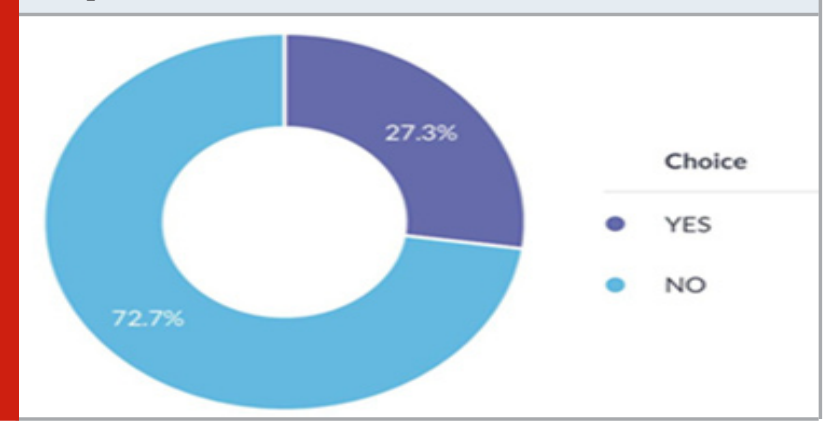

Figure 3: This pie chart represents percentage distribution of responses about awareness on treating lymphoma at the right stage. Purple denotes yes and blue denotes no that lymphoma can be cured at the right stage if diagnosed. Majority of the students (54.3\%) are not aware about treatment for lymphoma.

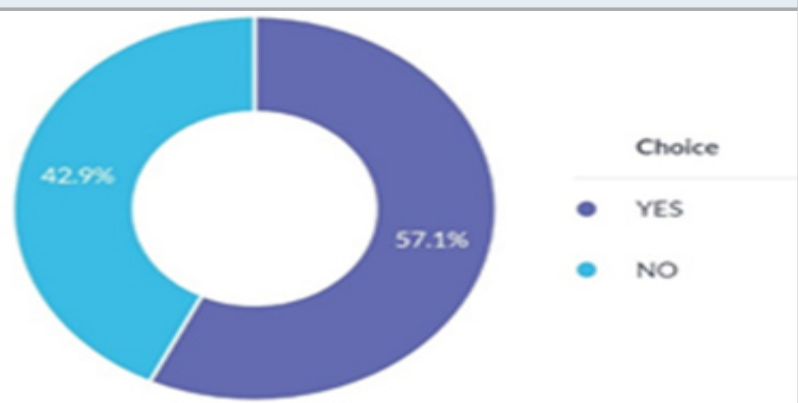


Figure 4: This pie chart represents percentage distribution of responses about awareness on lymphoma affecting the immune system. Purple denotes yes and blue denotes no that lymphomas affects the immune system. Most of the students (57.1\%) are aware about lymphoma adverse effects on the immune system.

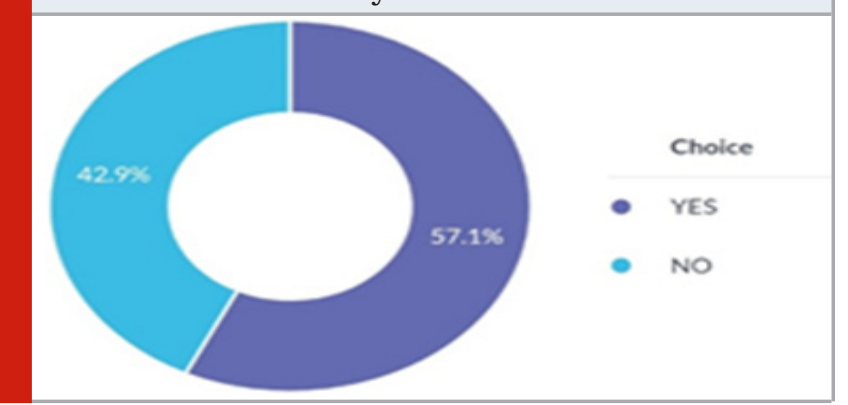

Figure 5: This pie chart represents percentage distribution of responses about awareness on chemotherapy and radiation used to treat lymphoma. Purple denotes yes and blue denotes no about treatment for lymphoma. Majority of the students (68.7\%) are aware that chemotherapy and radiation are performed to treat lymphoma.
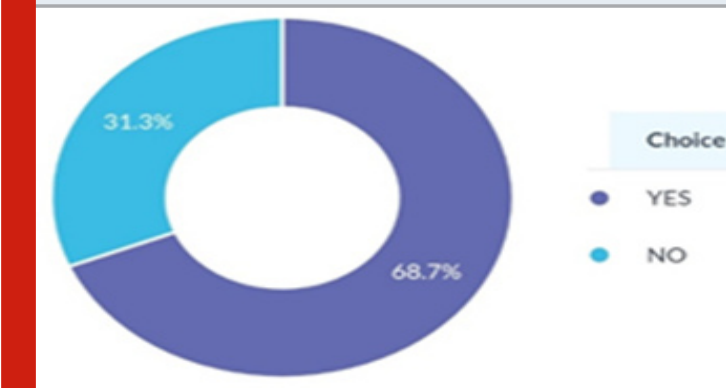

The purpose of this study is to create awareness about the various risk factors of lymphoma. The main risk factors are,

- AGE: Older people of age group 60-70 tend to develop non-Hodgkin lymphoma than others (Hartge and Devesa, 1992) (Feugier et al., 2004).

- GENDER: Men are more likely to develop lymphoma than women (Hartge and Devesa, 1992) (Cantor et al., 1993) (Roos and De Roos, 2003).

- IMMUNE DEFICIENCY DISORDER: people who have HIV/AIDS are more prone to develop lymphoma (Filipovich et al., 1992) (Smedby et al., 2006).

- AUTOIMMUNiTY AND INFLAMMATION: The updates review that many findings on risk, risk factors and lymphoma characteristics that have been presented recently in relation to a broad range of chronic inflammatory, including autoimmune conditions (Smedby et al., 2006).

- $\quad$ GENETIC RISK: First degree relatives of NHL, HL and CLL patients are more likely to show incidence of the risk factors to develop NHL, HL and CLL respectively (Cerhan and Slager, 2015). Clinical trials on going on to identify whether lymphoma is inherited or not (Filipovich et al., 1992).
Previous studies state that nearly $25 \%$ of the people will develop tumors, primary b-cell lymphoma when they are genetically immunodeficient (Filipovich et al., 1992). Increased risk of malignant lymphomas is associated consistently with certain autoimmune and inflammatory conditions like rheumatoid arthritis [RA] and Sjogren's syndrome, but it's still not validated that all the inflammatory conditions are associated with lymphoma in general (Papageorgiou et al., 2015). Most of the previous conducted studies were mainly focused on association of lymphoma with genetics and inflammatory disorders. Comparison of this study with the previous literature risk factors are easily understood by the people when it's more understandable than comprehensive. Various risk factors include age, gender, race and ethnicity, immune deficiency disorders, genetics and radiation exposure.

\section{CONCLUSION}

In this study, awareness about the complexities lymphoma were asked and concluded that 94\% of the survey participants were aware that lymphoma is a type of blood cancer and it is a threatening disease. It further causes impairment of the immune system and it can be cured at the right stage of diagnosis. Advancement in treatment modalities have improved the prognosis of patients with lymphoma. Awareness camps, seminars may be conducted to create awareness on the risk factors of lymphoma among the students. Future research may be required to study the apoptotic markers and therapeutics in different types of lymphoma.

\section{ACKNOWLEDGEMENTS}

The team extends our sincere gratitude to the Saveetha Dental College and Hospitals for their constant support and successful completion of this work.

\section{Conflict of Interest: Nil}

\section{REFERENCES}

Agathangelidis A, Rosenquist R, Davi F, et al. (2019) Immunoglobulin Gene Analysis in Chronic Lymphocytic Leukemia. Methods in Molecular Biology. DOI: 10.1007/978-1-4939-8876-1_5.

Allgar VL and Neal RD (2005) Delays in the diagnosis of six cancers: analysis of data from the National Survey of NHS Patients: Cancer. British Journal of Cancer. DOI: 10.1038/sj.bjc.6602587.

Ball P (2017) Is fertility and its preservation discussed with girls undergoing treatment for cancer? Andrology \&t Gynecology: Current Research. DOI: 10.4172/23274360-c1-003.

Cantor KP, Blair A, Brown LM, et al. (1993) Correspondence re: K. P. Cantor et al., pesticides and other agricultural risk factors for non-Hodgkin's lymphoma among men in Iowa and Minnesota, Cancer Res., 52: 2447-2455, 1992. Cancer research. 
Cartwright R, McNally R and Staines A (1994) The increasing incidence of non-Hodgkin's lymphoma (NHL): the possible role of sunlight. Leukemia \& lymphoma 14(5-6): 387-394.

Cartwright R, Brincker H, Carli PM, et al. (1999) The rise in incidence of lymphomas in Europe 1985-1992. European journal of cancer 35(4): 627-633.

Cartwright RA (1992) Changes in the descriptive epidemiology of non-Hodgkin's lymphoma in Great Britain? Cancer research 52(19 Suppl): 5441s-5442s. Cerhan JR and Slager SL (2015) Familial predisposition and genetic risk factors for lymphoma. Blood 126(20): 2265-2273.

Chen F, Tang Y, Sun Y, et al. (2019) 6-shogaol, a active constiuents of ginger prevents UVB radiation mediated inflammation and oxidative stress through modulating NrF2 signaling in human epidermal keratinocytes (HaCaT cells). Journal of photochemistry and photobiology. B, Biology 197: 111518.

Di Lollo S Picoco C MG (n.d.) Incidence rates of leukemias,lymphomas and myelomas in Italy: geographic distribution and NHL histotypes. DOI: 3.0.co;2x">10.1002/(sici) 1097-0215(19961009)68:2<156::aidijc2>3.0.co;2-X.

Elliss-Brookes L, McPhail S, Ives A, et al. (2012) Routes to diagnosis for cancer - determining the patient journey using multiple routine data sets. British journal of cancer 107(8): 1220-1226.

Feugier P, Virion JM, Tilly H, et al. (2004) Incidence and risk factors for central nervous system occurrencein elderly patients with diffuse large-B-cell lymphoma: influenceof rituximab. Annals of Oncology. DOI: 10.1093/annonc/mdh013.

Filipovich AH, Mathur A, Kamat D, et al. (1992) Primary immunodeficiencies: genetic risk factors for lymphoma. Cancer research 52(19 Suppl): 5465s-5467s.

Groves FD, Linet MS, Travis LB, et al. (2000) Cancer surveillance series: non-Hodgkin's lymphoma incidence by histologic subtype in the United States from 1978 through 1995. Journal of the National Cancer Institute 92(15). Oxford University Press: 1240-1251.

Hadzidimitriou A, Agathangelidis A, Darzentas N, et al. (2011) Is there a role for antigen selection in mantle cell lymphoma? Immunogenetic support from a series of 807 cases. Blood 118(11): 3088-3095.

Harris NL, Jaffe ES, Diebold J, et al. (2000) Lymphoma classification - from controversy to consensus: The R.E.A.L. and WHO Classification of lymphoid neoplasms. Annals of Oncology. DOI: 10.1093/annonc/11.suppl_1. s3.

Hartge P and Devesa SS (1992) Quantification of the impact of known risk factors on time trends in nonHodgkin's lymphoma incidence. Cancer research 52(19
Suppl): 5566s-5569s.

Hjalgrim H, Frisch M, Begtrup K, et al. (1996) Recent increase in the incidence of non-Hodgkin's lymphoma among young men and women in Denmark. British journal of cancer 73(7): 951-954.

Howell DA, Smith AG and Roman E (2006) Lymphoma: variations in time to diagnosis and treatment. European journal of cancer care 15(3): 272-278.

Jemal A, Siegel R, Ward E, et al. (2008) Cancer statistics, 2008. CA: a cancer journal for clinicians 58(2): 7196.

Ke Y, Al Aboody MS, Alturaiki W, et al. (2019) Photosynthesized gold nanoparticles from Catharanthus roseus induces caspase-mediated apoptosis in cervical cancer cells (HeLa). Artificial cells, nanomedicine, and biotechnology 47(1): 1938-1946.

Kostareli E, Gounari M, Agathangelidis A, et al. (2012) Immunoglobulin gene repertoire in chronic lymphocytic leukemia: insight into antigen selection and microenvironmental interactions. Mediterranean journal of hematology and infectious diseases 4(1): e2012052.

Liu S, Semenciw R and Mao Y (2003) Increasing incidence of non-Hodgkin's lymphoma in Canada, 1970-1996: age-period-cohort analysis. Hematological Oncology. DOI: 10.1002/hon.703.

Li Z, Veeraraghavan VP, Mohan SK, et al. (2020) Apoptotic induction and anti-metastatic activity of eugenol encapsulated chitosan nanopolymer on rat glioma C6 cells via alleviating the MMP signaling pathway. Journal of Photochemistry and Photobiology B: Biology. DOI: 10.1016/j.jphotobiol.2019.111773.

Lynce F, Pehlivanova M, Catlett J, et al. (2012) Obesity in Adult Lymphoma Survivors. Leukemia \&t Lymphoma. DOI: 10.3109/10428194.2011.619606.

Ma Y, Karunakaran T, Veeraraghavan VP, et al. (2019) Sesame Inhibits Cell Proliferation and Induces Apoptosis through Inhibition of STAT-3 Translocation in Thyroid Cancer Cell Lines (FTC-133). Biotechnology and bioprocess engineering: BBE 24(4): 646-652.

McNally RJ, Alexander FE, Staines A, et al. (1997) A comparison of three methods of analysis for age-periodcohort models with application to incidence data on non-Hodgkin's lymphoma. International journal of epidemiology 26(1): 32-46.

McNally RJQ, Roman E and Cartwright RA (1999) Leukemias and lymphomas: time trends in the UK, 1984-93. Cancer causes \& control: CCC 10(1): 35-42. Neal RD, Din NU, Hamilton W, et al. (2014) Comparison of cancer diagnostic intervals before and after implementation of NICE guidelines: analysis of data from the UK General Practice Research Database. British journal of cancer 110(3): 584-592. 
Papageorgiou A, Voulgarelis M and Tzioufas AG (2015) Clinical picture, outcome and predictive factors of lymphoma in Sj囚gren syndrome. Autoimmunity reviews 14(7): 641-649.

Ponnulakshmi R, Shyamaladevi B, Vijayalakshmi P, et al. (2019) In silico and in vivo analysis to identify the antidiabetic activity of beta sitosterol in adipose tissue of high fat diet and sucrose induced type- 2 diabetic experimental rats. Toxicology mechanisms and methods 29(4): 276-290.

Postgraduate Haematology (2015) WHO Classification: Tumours of the Haematopoietic and Lymphoid Tissues (2008). DOI: 10.1002/9781118853771.ch51.

Richards M, Corner J and Maher J (2011) The National Cancer Survivorship Initiative: new and emerging evidence on the ongoing needs of cancer survivors. British journal of cancer 105 Suppl 1: S1-4.

Roos AJD and De Roos AJ (2003) Integrative assessment of multiple pesticides as risk factors for nonHodgkin's lymphoma among men. Occupational and Environmental Medicine. DOI: 10.1136/oem.60.9.e11. Seow A, Lee J, Sng I, Fong CM, Lee HP (n.d.) NonHodgkin's lymphoma in an Asian population: 1968 - 1992-time trends and ethnic differences in Singapore. DOI: 3.0.co;2-u">10.1002/(sici) 10970142(19960501)77:9<1899::aid-cncr21>3.0.co;2-u. Smedby KE, Baecklund E and Askling J (2006) Malignant lymphomas in autoimmunity and inflammation: a review of risks, risk factors, and lymphoma characteristics. Cancer epidemiology, biomarkers \&t prevention: a publication of the American Association for Cancer Research, cosponsored by the American Society of Preventive Oncology 15(11): 2069-2077. ST Boyle P Holford TR Liu WL Flannery J ZTM (n.d.) Epidemiology of non-Hodgkin lymphoma in Connecticut from 1935 to 1988. DOI: 3.0.co;2i"> 10.1002/1097-0142(19920815)70:4<840::aidcncr2820700420>3.0.co;2-i.

Swann R, McPhail S, Witt J, et al. (2018) Diagnosing cancer in primary care: results from the National Cancer Diagnosis Audit. The British journal of general practice: the journal of the Royal College of General Practitioners 68(666): e63-e72.

Varterasian ML, Graff JJ, Severson RK, et al. (2000) NonHodgkin's lymphoma: an analysis of the Metropolitan Detroit SEER database. Cancer investigation 18(4): 303-308.

Wang G, Cao C, Yu Q, et al. (2017) Atopic Diseases Correlated with the Incidence of Cancer. Chemo Open Access 6(225): 2.

Wu F, Zhu J, Li G, et al. (2019) Biologically synthesized green gold nanoparticles from Siberian ginseng induce growth-inhibitory effect on melanoma cells (B16). Artificial cells, nanomedicine, and biotechnology 47(1): 3297-3305.

Zheng L, Wang QF, Jiang T, et al. (2017) Bilateral adrenal primary diffuse large b-cell lymphoma not accompanied by adrenal insufficiency: A report of two cases. Chemotherapy 6: 2 . 